\title{
SOBRE A VIOLÊNCIA HOMOFÓBICA NA EDUCAÇÃO BRASILEIRA*
} ON HOMOPHOBIC VIOLENCE IN BRAZILIAN EDUCATION

\author{
Sheila Giardini Murta, Isabela de Oliveira Rosa, Jordana Calil Lopes de Menezes, \\ Marcella Regina Silva Rieiro, Ohary de Sousa Borges, \\ Verônica de Oliveira e Silvia Guimarães de Paulo \\ Universidade de Brasília, Brasília-DF, Brasil \\ Victor Hugo de Miranda \\ Pontifícia Universidade Católica de Goiás, Goiânia, Brasil
}

O papel do sistema educacional no combate ${ }^{1}$ à homofobia e na promoção do livre exercício do direito à orientação sexual é o tema do livro Homofobia e Educação: Um Desafio ao Silêncio, organizado por Tatiana Lionço e Débora Diniz (2009) e editado pela Editora da UnB e LetrasLivres (Brasília, 196 p.). O livro discute, por um lado, a relativa negligência do sistema educacional brasileiro frente ao tema, e por outro, as iniciativas nascentes nas políticas públicas educacionais dos últimos anos, no sentido de tornar a escola um espaço de pertencimento e inclusão das diversidades sexuais. A obra adota uma perspectiva multidisciplinar, contando com a colaboração de doze profissionais, com formação nas áreas de Educação, Direito, Antropologia, Comunicação, Sociologia, História, Psicologia e Serviço Social. Grande parte dos autores está afiliada a universidades (Universidade de São Paulo, Universidade de Paris X - Nanterre, Universidade de Brasília, Universidade Federal da Bahia e Universidade Federal do Rio Grande do Sul), alguns estão afiliados a ONGs (Organização Não-Governamental Nuances, Organização Não-Governamental Corsa) e outros a institutos de pesquisa (Anis - Instituto de Bioética, Direitos Humanos e Gênero e Instituto Nacional de Estudos e Pesquisas Educacionais Anísio Teixeira).

O livro está organizado em oito capítulos. O Capítulo 1, Qual a Diversidade Sexual dos Livros Didáticos Brasileiros, escrito por Lionço e Diniz, é introdutório e aborda os custos psicossociais resultantes da marginalização vivida pelos homossexuais, como a desinformação, a solidão, a vergonha, a insegurança, a timidez e a exclusão de oportunidades sociais e profissionais. As autoras afirmam que os livros didáticos brasileiros omitem a diversidade sexual e apresentam a sexualidade numa perspectiva estritamente biológica. Além disto, as relações de gênero são apresentadas nos livros didáticos numa ótica heteronormativa, o que contribui para a homofobia. A capacitação de professores e a inclusão adequada da diversidade sexual no material didático são recomendadas para que a escola atue como espaço de pertencimento.
O capítulo seguinte, A Homofobia, de Borrillo, discute a definição, as origens, as manifestações e o impacto da homofobia. Este termo foi criado no fim dos anos 90 e se refere à reações de hostilidade contra homossexuais, baseadas no entendimento de que a homossexualidade é anti-natural, patológica ou inferior. Tem na base o sexismo, que é a crença de superioridade de um gênero (masculino) sobre o outro (feminino). A homofobia se expressa desde manifestações sutis, como simpatizar com homossexuais mas rejeitar a política de igualdade de direitos, até manifestações explicitamente excludentes, como insultos, exterminação e negação de direitos (por exemplo, o direito ao casamento concedido apenas na Espanha, Bélgica, Canadá e Holanda, à adoção, à reprodução assistida e à igualdade patrimonial). Borrillo lembra que a violência homofóbica é também dirigida a mulheres heterossexuais com personalidades fortes e homens heterossexuais com grande sensibilidade ou delicados, que são punidos por um processo cultural chamado pelo autor de "vigilância de gênero" contra todos que se desviam do "gênero certo". A estigmatização cotidiana pelo outro, na forma de piadas, injúrias, depreciação, compaixão, rotulação com doente e negação de direitos, passa a ser a autoestigmatização ou violência interiorizada. Esta resulta em culpa, ansiedade, vergonha e depressão, não raro levando ao término do desejo de viver. Considerando a perspectiva do aluno homossexual, este se torna isolado na escola, tem suas redes sociais diminuídas, com vínculos feitos na clandestinidade, e a educação sexual e afetiva prejudicada. $\mathrm{O}$ autor encerra o capítulo discutindo o papel dos diferentes atores sociais, escola, profissionais e familiares, no sentido de se capacitarem para compreender e abordar a homossexualidade como sendo tão legítima quanto a heterossexualidade.

No terceiro capítulo, Homofobia, Silêncio e Naturalização: por uma Narrativa da Diversidade Sexual, Lionço e Diniz descrevem os resultados do estudo "Qual a diversidade sexual dos livros didáticos brasileiros?". Esse estudo analisou como o tema da diversidade sexual foi apresentado em 67 livros didáticos 
e 25 dicionários, distribuídos nas escolas públicas, entre os anos de 2007 e 2008. Entre os livros didáticos foram examinados livros das disciplinas de alfabetização, português, ciências e história, em relação ao ensino fundamental e os das disciplinas de português, biologia e história do ensino médio. As obras foram analisadas por quatro pesquisadores que consideraram três categorias: homofobia: manifestações de hostilidade em relação a não-heterossexualidade; silêncio: omissão da diversidade sexual em contextos que ela deva ser considerada; e naturalização da heterossexualidade (heteronormatividade): tomar a heterossexualidade como o referencial normativo nas relações sexuais e afetivas. Os pesquisadores constataram que (a) os livros didáticos tratam a sexualidade unicamente na perspectiva biológica e de prevenção de doenças, omitindo suas dimensões social e afetiva; (b) os dicionários conceituam práticas sexuais e afetivas não-heterossexuais como patológicas e antinaturais e (c) os livros didáticos não contêm expressões homofóbicas, contudo adotam uma perspectiva heteronormativa em relação à família e à sexualidade.

No capítulo 4, A Eloqüência do Silêncio: Gênero e Diversidade Sexual nos Conceitos de Família Veiculados por Livros Didáticos, Vianna e Ramires tratam de como a diversidade sexual é trabalhada nos conceitos de família dos livros didáticos utilizados pelas escolas. Afirmam que a noção de família está carregada de sentidos que remetem às relações e às desigualdades de gênero e que o livro didático continua sendo veículo para tal discriminação. Concluem que hoje, como parte de qualquer processo de transformação, a maneira com que o livro didático aborda as configurações e relações familiares, apresenta contradições entre mudanças e permanências de padrões estereotipados. Nesse sentido, há indícios de uma nova visão, que questiona a forma hegemônica de uma família nuclear (heterossexual), branca e de classe média como sendo o padrão de normalidade. No entanto, há ausência da diversidade sexual, ou seja, nenhuma alusão é feita à variação da orientação sexual. Segundo eles, a aluna ou aluno não se identifica com um homossexual quando toma como referência a família heteronormativa que lhe é apresentada. Dessa forma, pode-se perceber que as mudanças abordadas nos livros didáticos hoje são ainda insuficientes para desafiarem as práticas heterossexistas da escola.

O capítulo 5, Ilustrações do Silêncio e da $\mathrm{Ne}$ gação, escrito por Fontes, discute o silêncio da escola sobre a diversidade sexual como negligência que facilita a manutenção e do preconceito. Informa que a incidência de assassinatos por discriminação sexual no Brasil está entre as maiores do mundo. $\mathrm{O}$ autor ressalta o antagonismo entre a omissão da diversidade sexual nos livros didáticos, e a produção da televisão brasileira, que têm abordado a temática em suas telenovelas, o que mostra uma inclusão na agenda sociocultural, embora estas ainda estejam longe da promoção da igualdade na diversidade sexual. Ainda que a educação sexual na escola esteja prevista na lei brasileira, sua implementação tem sido dificultada por setores da igreja católica e da sociedade em geral. Conclui ser fundamental, em uma sociedade voltada para a inclusão da diversidade, a criação de estratégias de desconstrução de preconceitos na educação básica.

No sexto capítulo, intitulado Cores e Dores do Preconceito: entre o Boxe e o Balé, Pocahy, Oliveira e Imperatori descrevem uma tentativa de inserção de discussões sobre a diversidade sexual encontrada em um livro de sétima série, dentre os vários analisados, por meio de exercícios de discussão e comparação entre os filmes "Billy Eliot" (em que um adolescente escolhe dançar balé) e "Menina de Ouro" (a personagem central é uma jovem que pratica boxe). No entanto, tal tentativa foi bastante incipiente, pois as questões sugerem discussões mais voltadas para a escolha da profissão e gênero, ficando a abordagem reflexiva sobre heteronormatividade, preconceito, homossexualidades, orientação sexual, entre outros, apenas a cargo do professor que possua abertura para tanto. Os autores concluem que esta é uma iniciativa de valor, mas incompleta tendo em vista a escola como promotora de cidadania e dos direitos humanos de gays, lésbicas, bissexuais, travestis e transexuais.

Rios e Santos abordam no penúltimo capítulo, Diversidade Sexual, Educação e Sociedade: Reflexões a partir do Programa Nacional do Livro Didático, a inserção da diversidade sexual nas políticas educacionais no Brasil, a partir do Programa Nacional do Livro Didático (PNLD). Apontam os principais marcos, nas últimas décadas, que levaram à inserção da discriminação por orientação sexual e identidade de gênero nas políticas públicas, mostrando nesta trajetória que a afirmação da sexualidade como digna de proteção é muito recente. Uma evidência disto é que a proibição da discriminação por orientação sexual iniciou-se apenas em meados dos anos 90. Defendem o pressuposto de que o conteúdo dos livros para o PNLD deve contemplar aspectos éticos e de cidadania. Mas, a análise dos livros didáticos brasileiros mostra uma timidez em lidar com a diversidade sexual, pois não basta eliminar conteúdo homofóbico. É também necessário reconhecer esta diversidade nos livros e, assim, caminhar para o fortalecimento democrático e respeito aos direitos, o que é fundamental no processo educacional. Concluem que, como o papel do PNLD é promover os princípios democráticos no processo educacional, é preciso que esta temática seja trabalhada nas escolas através dos livros didáticos, pois eles afetam diretamente a construção do conhecimento e da capacidade de analisar a realidade que cerca os estudantes. 
A obra é encerrada com o capítulo de Junqueira, Políticas de Educação para a Diversidade Sexual: Escola como Lugar de Direitos. O autor relata que o desenvolvimento de condições satisfatórias para lidar com os direitos sexuais nas escolas depende de políticas públicas de educação e de mobilização social que visem à desconstrução da heteronormatividade. Estas políticas educacionais devem ter caráter inclusivo e inserir a diversidade sexual de modo claro nas diretrizes de ensino. Argumenta que a formação inicial e continuada dos professores deve incluir a diversidade sexual e os direitos sexuais. Além da formação profissional, a composição de diretrizes e a elaboração de materiais que abordem concepções de gênero não heterossexistas se fazem necessários para o enfrentamento de discriminações por orientação sexual e para a transformação da escola como lugar de direitos em geral, e direitos sexuais, em particular.

Portanto, esta é uma obra necessária para todos os que se ocupam de políticas públicas educacionais, da formação de professores, dos direitos humanos e da promoção de saúde mental. O "desafio ao silêncio", como diz o subtítulo do livro, frente à homofobia na educação, faz lembrar também a vergonhosa negligência da Psicologia frente ao tema. Pior do que a negligência é a contribuição direta de pretensos saberes psicológicos para o entendimento da homossexualidade como sendo patológica ${ }^{2}$. Diversas gerações de psicólogos foram ensinados a crer que a homossexualidade resulta de desajustes familiares ou abuso sexual na infância, legitimando assim condutas profissionais discriminatórias de grave impacto. Na Psicologia brasileira, a desconstrução da homossexualidade como doença e desajustamento é algo recente. Há apenas pouco mais de dez anos, o Conselho Federal de Psicologia - CFP (Conselho Federal de Psicologia, 1999) lançou uma resolução que estabelece parâmetros para a atuação do psicólogo com pessoas com identidades de gênero LGBT (Lésbicas, Gays, Bissexuais, Travestis, Transexuais e Transgêneros), impedindo qualquer participação deste profissional em ações "curativas" da homossexualidade, no intuito de eliminar práticas profissionais regidas pela concepção da homossexualidade como antinatural. Nos Estados Unidos, Schneider, Brown \& Glassgold (2002) publicaram um artigo dirigido aos psicólogos daquele país visando auxiliá-los no cumprimento de uma resolução similar à do CFP lançada pela Associação Americana de Psicologia (APA) em 1998, com orientações básicas para se prestar serviços psicológicos competentes técnica e eticamente, conforme os princípios da beneficência, não maleficência e autonomia. Estes autores esclarecem que a sexualidade não se organiza em categorias binárias, homo ou heterossexual, mas em categorias contínuas, com a possibilidade de diversas expressões da sexualidade no curso da vida; que a homossexualidade não é um fenômeno estável ao longo da vida, com chance de flutuações na escolha do parceiro (o que não significa que a homossexualidade possa ser eliminada ou curada); que a oportunidade, ou falta de oportunidade, pode influenciar a escolha do parceiro sexual do mesmo sexo; que famílias desestruturadas e abuso sexual na infância não são fatores causais da homossexualidade e que os transtornos mentais entre homossexuais não são causados pela homossexualida$\mathrm{de}$, mas resultam da cultura heterossexista que exclui e oprime as identidades sexuais não heterossexuais.

Uma análise da literatura brasileira e estrangeira em prevenção ao sexismo (Schwartz \& Lindley, 2009) e ao heterossexismo (Borges \& Meyer, 2008; Matthews \& Adams, 2008) mostra que este último é um tema "esquecido" também pelos cientistas. Enquanto a produção em Psicologia acerca da violência contra a mulher é vasta, a produção acerca da homofobia é reveladoramente restrita. Obviamente, a clandestinidade em torno do tema direciona a produção científica, como também direciona a ação de políticos, gestores, líderes religiosos e professores. Assim, lidar com os obstáculos culturais na implementação do Programa Brasil sem Homofobia: Programa de Combate à Violência eà Discriminação contra GLBT e de Promoção de Cidadania Homossexual e da adequada inserção da diversidade sexual nos livros didáticos brasileiros é, sem dúvida, o principal desafio. A esse respeito, o recente retrocesso na aprovação do III Programa Nacional dos Direitos Humanos, onde os direitos sexuais estão também tratados, mostra o veemente conservadorismo de alguns setores de nossa sociedade. Felizmente, mudanças culturais também podem ser gradualmente promovidas a partir de discussões em pequenos grupos, como as vivenciadas em salas de aula (a exemplo do trabalho de Sieben \& Wallowitz, 2009). Nessa perspectiva, a cada dia microrrevoluções podem ter lugar, quando compromissos éticos são assumidos no modo de fazer ensino, pesquisa e política. Oxalá a obra Homofobia e Educação: um Desafio ao Silêncio ocupe outros espaços além das prateleiras das bibliotecas e possa sim vir a ser uma das vias instigadoras para a tão necessária revolução de ideias que precisamos e para a integração entre a academia, a sociedade civil e o governo, rumo a uma sociedade de direitos.

\section{Notas}

* Os autores agradecem ao CNPq o apoio recebido (Processo 551319/2007-0).

1 O termo "combate", nesse contexto, tem origem na militância na área dos direitos sexuais. Devido ao seu caráter claramente político, o termo gera controvérsias em parte do meio edu- 
cacional, que se serve do argumento de que não é papel da escola defender qualquer movimento social e "combater", por exemplo, a homofobia, o sexismo ou o machismo. Contudo, esta argumentação, protegida pelo escudo da neutralidade da escola, acaba por retardar a contribuição da educação formal na promoção de uma sociedade mais justa e inclusiva.

2 Para aprofundamento sobre as correntes patologizante e afirmativa da homossexualidade em saúde mental, recomendamos consultar entrevista concedida por Jack Drescher (2010). Uma outra referência complementar sobre a atuação do psicólogo neste contexto é: Sanders (1994).

\section{Referências}

Borges. Z, N. \& Meyer, D. E. (2008). Limites e possibilidades de uma ação educativa na redução da vulnerabilidade à violência e à homofobia. Avaliação e Políticas Públicas em Educação, 16, 59-76.

Conselho Federal de Psicologia. (1999). Resolução CFP 001/99 - Estabelece normas de atuação em relação à orientação sexual. Brasília: FP.

Drescher, J. (2010). Psicoterapia e guerras culturais [Entrevista]. Centro Latino-americano em sexualidade e direitos humanos (CLAM). Acesso em 05 de abril, 2010, em http://www.clam. org.br/publique/cgi/cgilua.exe/sys/start.htm?UserActiveTem plate $=\% 5$ FBR \&infoid $=6489 \&$ query $=$ simple $\&$ search $\% 5$ Fby $\% 5$ Fauthorname $=$ all\&search $\% 5$ Fby $\% 5$ Ffield $=$ tax \&search $\% 5$ Fby $\% 5$ Fheadline $=$ false $\&$ search $\% 5$ Fby $\% 5$ Fkeywords $=$ any $\&$ search $\% 5 \mathrm{Fby} \% 5 \mathrm{Fpriority}=$ all\&search $\% 5 \mathrm{Fby} \% 5 \mathrm{Fsection}=\mathrm{al}$ $1 \&$ search $\% 5$ Fby $\% 5$ Fstate $=$ all $\&$ search $\% 5$ Ftext $\% 5$ Foptions $=\mathrm{a}$ $11 \&$ sid $=43 \&$ text $=$ jack + drescher

Lionço, T. \& Diniz, D. (2009). Homofobia e educação: um desafio ao silêncio. Brasília: Letras Livres; EdUnB.

Matthews, C. R. \& Adams, E. M. (2008). Using a social justice approach to prevent the mental health consequences of hetero sexism. Journal Primary Prevent, 30, 11-26.

Sanders, G. L. (1994). O amor que ousa declarar seu nome: do segredo à revelação nas afiliações de gays e lésbicas. In E. Imber-Black (Org.), Os segredos na família e na terapia familiar (D. Batista, Trad ., pp. 219-244). Porto Alegre: Artes Médicas.

Schneider, M. S., Brown, L. S., \& Glassgold, J. M. (2002). Implementing the resolution on appropriate therapeutic responses to sexual orientation: a guide to the perplexed. Professional Psychology: Research and Practice, 33, 265-276.
Schwartz, J. P. \& Lindley, L. D. (2009). Impacting sexism through social justice prevention: implications at the person and environmental levels. Journal of Primary Prevention, 30, 27-41.

Sieben, N. \& Wallowitz, L. (2009). "Watch what you teach": a first-year teacher refuses to play it safe. English Journal, 98, 44-49.

Recebido em: 09/12/2009

$1^{\text {a }}$. Revisão em: 16/02/2010

$2^{\text {a }}$. Revisão em: 07/04/2010

Aceite em: 26/05/2010

Sheila Giardini Murta é Profa. Adjunta do Departamento de Psicologia Clínica - UnB. Endereço: Departamento de Psicologia Clínica, Instituto de Psicologia, Universidade de Brasília, Campus Darcy Ribeiro, Brasília-DF, Brasil. CEP 70910-900.

E-mail: giardini@unb.br

Isabela de Oliveira Rosa, Jordana Calil Lopes de Menezes, Marcella Regina Silva Rieiro, Verônica de Oliveira e Silvia Guimarães de Paulo são Psicólogas, Bolsistas de Apoio Técnico - CNPq no Departamento de Psicologia Clínica/UnB.

Ohary de Sousa Borges é Enfermeiro, Bolsista de Apoio Técnico - CNPq no Departamento de Psicologia Clínica/UnB.

Victor Hugo de Miranda é Auxiliar de Pesquisa Voluntário, Graduando em Psicologia na Pontifícia Universidade Católica de Goiás.

\section{Como citar:}

Murta, S. G., Rosa, I. O., Menezes, J. C. L., Rieiro, M. R. S., Oliveira, V., Paulo, S. G., Borges, O. S., \& Miranda, V. H. (2011). Sobre a Violência Homofóbica na Educação Brasileira. Psicologia \& Sociedade, 23(2), 438-441. 